\title{
Ю.Н. Варфоломеева
}

\section{КЛАССИФИКАЦИЯ ГЛАГОЛЬНЫХ ПРЕДИКАТОВ В ОПИСАТЕЛЬНЫХ ТЕКСТАХ ПУБЛИЦИСТИЧЕСКОГО СТИЛЯ ${ }^{1}$}

\begin{abstract}
Приведена семантическая классификация глагольных предикатов в описательных текстах публицистического стиля, предполагающая выделение трех блоков единиц: 1) предикаты, традиционно связываемые с категорией пространства, - неакииональные предикаты зрительной периепчии (предикаты номинации пространственных параметров одного объекта в отночении другого и вербализащии собственных пространственных характеристик объекта); 2) интермодальные неакииональные единицьы; 3) акциональные предикаты.

Ключевые слова: описательный текст, публицистический стиль, глагольный предикат, перцепиия, классификачия предикатов, текстовая модель.
\end{abstract}

Текст типа «описание», в основе которого лежит перечисление синхронных признаков предмета, воспринимаемых в определенный момент времени, обусловливает специфику функционирования глагольных предикатов. Разработанная текстовая модель описательного текста включает фигуру наблюдателя, в поле зрения которого входят некоторое пространство, а также некоторый фон (семантика существования) и когнитивно выделенные фигуры (актанты) [1]. Семантика существования вербализуется глагольными предикатами с бытийной семантикой. При подробной разработанности актантной части модели описания область предикатной составляющей остается недостаточно исследованной.

В лингвистике до настоящего момента остается ряд вопросов, затрагивающих разные классификации глагольных единиц: объем и границы вычленяемых глагольных разрядов, их число, принципы выделения. В языкознании существует значительное число работ, в которых содержатся классификации глагольных единиц с выделением внутри групп глаголов на основе разных критериев (исследования Ю.Д. Апресяна [2], Т.В. Булыгиной и А.Д. Шмелева [3], Л.М. Васильева [4], Е.Ю. Владимирского, М.В. Всеволодовой [5], Р.М. Гайсиной [6], Е.В. Падучевой [7] и др.). В частности, выделяются более общие и более конкретные классификации. В классификациях первого типа все глаголы делятся на глаголы действия и состояния, в классификациях второго типа выделяются глаголы состояния,

\footnotetext{
${ }^{1}$ Исследование выполнено при финансовой поддержке гранта «Молодые ученые Восточно-Сибирского государственного университета технологий и управления 2019». Проект: «Семантические типы глагольных предикатов: нарратологический и когнитивный анализ».
} 
отношения, процесса, действия и др. Кроме того, важно, какой признак положен в основу классификации: аспектуальная характеристика действия, семантика, синтагматический принцип и др. Особый интерес представляют единицы пространственной семантики (М.В. Всеволодова [5], Л.В. Гукина [8], Л.Н. Федосеева [9], K.S. Mix, L.B. Smith, M. Gasser [10] и др.). Возникновение лингвистики пространства - нового направления в языкознании свидетельствует о растущем интересе ученых к данной области исследования.

В статье предлагается классификация глагольных предикатов на основе семантических признаков, в результате выделяются разные лексикосемантические группы (ЛСГ) глагольных предикатов (группы слов, объединенных общим основным компонентом значения [11. С. 229-239] или общими семантическими признаками [12. С. 110]). Слова входят в ЛСГ своими лексико-семантическими вариантами (ЛСВ). ЛСГ имеют подвижные границы, что обусловлено динамизмом их функционирования.

К критериям вычленения ЛСГ в настоящей статье относятся: 1) наличие общего значения всех глагольных предикатов описательного текста - значения бытия (выявленный глубинный смысл может быть обозначен как семантический кварк - регулярный смысл, который входит в состав семантики всех глагольных предикатов описательного текста [13. С. 291]); 2) способ существования объектов в пространстве, реализуемый через специфику восприятия, восприятие же, в свою очередь, можно разделить по видам анализаторов (аудиальное, ольфакторное и др.) и формам существования материи (восприятие движения, пространства, времени) [14. С. 3638]. Применительно к описательному тексту можно сказать, что данный тип текста вербализует пространство, которое воспринимается органами чувств [15. С.123].

Построение описательных текстов зависит от стилистической принадлежности фрагмента. Интерес к публицистическому стилю обусловлен тем, что основной корпус исследований типов речи, в том числе описательного, строится на анализе художественных ([16-19] и др.) и частично научных фрагментов [15]. Отдельные аспекты функционирования описания в официальноделовом стиле представлены в работах Л.Г. Кыркуновой [20, 21].

Анализ публицистических текстов выявляет дуализм их стилистической природы, поскольку построение описаний и семантическое разнообразие глагольных предикатов в одних жанрах (книги воспоминаний, эссе, очерки, туристические проспекты) оказываются близки художественному стилю (использование экспрессивных, окказиональных, стилистически ограниченных единиц), в других (например, информация на официальных сайтах органов государственной власти и т.п.) - к официально-деловому (специальные, книжные, нейтральные предикаты).

Для характеристики пространства в описании публицистического стиля могут быть использованы предикаты зрительной перцепции, традиционно связываемые с категорией пространства. В данном блоке единиц следует вычленить: а) предикаты, номинирующие пространственные характеристики предмета в отношении другого объекта (размещения в пространстве, 
позиции, охвата предмета, заполнения пространства, границ пространства, направления, пространственного соотношения предметов); б) предикаты, вербализующие собственные пространственные характеристики объекта (формы предмета, характеристики плоской поверхности, положения предметов в пространстве и выделенности в пространстве на основе световых / цветовых характеристик).

Перечислим ЛСГ предикатов и назовем их состав, иллюстрируя минимальными и полными контекстами употребления в разных жанрах публицистики.

Среди предикатов, номинирующих пространственные характеристики предмета в отношении другого объекта, могут быть вычленены ЛСГ слов со следующими конкретными значениями.

1. Глагольные предикаты со значением размещения в пространстве: во дворе располагается площуадка, детский сад стоит на горе, комната расположена на втором этаже и др.:

Еще одним немаловажным плюсом для инвесторов является транспортная доступность города. От МКАД до населенного пункта - 7 км, а ближайшая станция метро располагается всего в 10 минутах езды транспортом. Кроме того, Щербинка обладает железнодорожным сообщением с Москвой (Курский вокзал) (А. Ивушкина. Общественная палата вступилась за выселяемых на улицу жильцов Щербинки // Известия, НКРЯ).

2. Позиционные предикаты: вещзи валяются на полу, коммуникации проложены, этажерка стоит ${ }^{1}$ у дивана и др.:

Сейчас вместо игровых автоматов в помещении стоят два десятка столов с ЖК-мониторами, на которые выводятся результаты розыгрышей. А на входе перед стойкой администратора висит угрожающее объявление - в помещении, не делая ставок, можно находиться только 20 минут (Г. Петелин, А. Раскин. Дело «игорного» прокурора А. Игнатенко закроет суд // Известия, НКРЯ).

3. Предикаты с семантикой охвата предмета с разных сторон, погружения одного в другое: беседка увешана ияетами, дома купаются в тумане, платье облегает фигуру и др.:

Крой слегка приталенный, одна шлица. Брюки прямые, свободные, со стрелками и одним зашчипом. Рубашка зауженная книзу. Плотно облегает грудную клетку (А. Маянцева, фото А. Кара. Одеваем мужчину по типу фигуры // Комсомольская правда, НКРЯ).

4. Единицы со значением заполнения пространства: дом наполнен, старинной мебелью, парк заполнен детьми, полки уставлень безделушками и др.:

Комната уставлена моделями самолетов и кораблей. Мельчайшие детали, тончайшее сочетание цветов, невероятная похожесть...

\footnotetext{
1 Здесь следует отметить разные ЛСВ глагола стоять: в первом случае он характеризует предметы, которые могут иметь только одну позицию в пространстве (детский

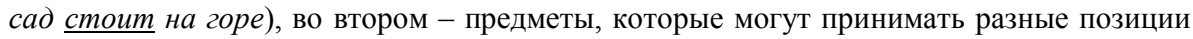
(этажерка стоит у стены / лежит на полу).
} 
(П. Садков. Дмитрий и Полина Дибровы: Сын Саша точно будет работать на телевидении! // Комсомольская правда, НКРЯ).

5. Предикаты, которые очерчивают границы пространства: дорога отделяет жилой комплекс от парка, зона ограничена по периметру, степи окружают юрту и др.:

"Шедевры барокко» заняли только Овальный зал - пьлиный и одновременно уютный, едва вмещзающий 200 человек. Публика рассажена по всему периметру, причем обладателей даже самых удаленных мест отделяem от исполнителей всего пять метров (Я. Тимофеев. Усадьба «Архангельское» разбавила джаз старинной музыкой // Известия, НКРЯ).

6. Предикаты, указывающие на направление в пространстве: дорога вела к дому, в середине зала дома проходит граница, тропа лежит на северо-восток и др.:

Обрывистый берег, по которому мы или, медленно пополз к воде Тыи. Тьия, словно спрут, впилась в Байкал сотнями своих щупальцев - ручьев и речек (М. Белоусов. БАМ, до востребований...).

В приведенном фрагменте использован предикат направления (берег пополз), выразительно представляющий пространственные отношения в публицистическом тексте.

7. Предикаты с семантикой пространственного соотношения предметов: шатер примыкал к забору, кресло примостилось у камина, камин вмонтирован в стену и др.:

Почти на всем протяжении дороги соснь слегка подталкивают своих нежных и красивых сестер - бельх берез (а их здесь очень мало) к самой обочине, словно очень хотят, чтобы люди видели их красоту. А они, как босоногие девчонки, жммтся к соснам и приветливо, смущенно ульбаются нам (М. Белоусов БАМ, до востребований...).

Данный пример содержит экспрессивные предикаты (подталкивают, жмутся).

К числу предикатов, презентующих собственные пространственные характеристики объекта, следует отнести следующие ЛСГ.

1. Глагольные предикаты с семантикой формы предмета: серпантин вbется, предметь громоздятся прямо посреди комнаты, глаза круглились и др.:

Туапсинский район тянется вдоль побережья - от бухты Инал на северозападе до поселка Шепси на юго-востоке. Дорога здесь то углубляется в гоpы, петляет между почти отвесными скалами, то неожиданно выворачивается почти к морю (А. Малкова. В отпуск на автомобиле // Труд-7, НКРЯ).

Приведенное описание, презентующее восприятие пейзажей Грузии, изобилует предикатами с пространственной семантикой, в числе прочих функционирует предикат формы (дорога петляет).

2. Единицы характеристики плоской поверхности объекта: песок ucслежен, пол затоптан, стены оклеены газетами и др.:

Высокие горы до самых вершин покрыты вековым лиственничным лесом. К берегу спускаются короткие отроги Кавказского хребта в дубовых и буковых рощуах (А. Малкова. В отпуск на автомобиле // Труд-7, НКРЯ). 
Текст содержит предикат характеристики плоской поверхности (горы nокрытыл).

3. Предикаты положения предметов в пространстве: степи простираются на восток, озеро разливается на километры, небоскребы возвышаются над городом и др.:

Тайга закуржавела, казалось, что она, укутавшись в белое пуховое одеяло, замерла в сонном очепенении <...> Хребты, которые бесконечной чередой тянулись по обеим сторонам, все сближались и, наконеи, сомкнулись у перевала Ангаракан, на 632 километре трассы БАМа (М. Белоусов. БАМ, до востребования...).

В этом примере глагольные предикаты используются не с семантикой развития действия во времени (тянулись, сближались, сомкнулись), а в пространстве, т.е. посредством подобных единиц указываются разные точки в системе координат: в одном месте хребты тянутся по обеим сторонам, в другой точке сближаются и на 632 километре смыкаются.

4. Предикаты со значением выделенности в пространстве на основе световых / цветовых характеристик: видны светящиеся окна, мерцают звезды, облака светлеются и др.:

Ее жилище напоминает музей. На каждом квадратном метре здесь живут сказочные персонажи: в ванной - русалка с пышным хвостом, на кухне - семья домовых, вырезанных из причудливых коряг, на потолке знаки зодиака и звезды, крупные, как в планетарии (в темноте они светятся и мериают), на стенах - лешие, Кот в сапогах, средневековые рыцчари и ульбающиеся львь (Н. Лескова. Читать я научилась по газете «Труд» // Труд-7, НКРЯ).

Рассмотренные ЛСГ глагольных предикатов свидетельствуют о разнообразии используемых в публицистике единиц, среди предикатов выявлены нейтральные (дом располагается вблизи, картина висит на стене и др.), экспрессивные (дорога ползет вперед, дома купаются в свете и др.), стилистически ограниченные единицы (вещи валяются, облака светлеются и др.), специализированные (объект вмонтирован в стену, коммуникаичи проложены и др.), свидетельствующие о стилистической дуалистичности публицистики.

Эмпирическая база настоящего исследования состоит из 684 описательных текстов публицистического стиля, в которых зафиксированы 1015 глагольных предикатов зрительной перцепции, 83 предиката интермодальной семантики и 30 акциональных глагольных предикатов. Часть примеров была отобрана в газетном корпусе Национального корпуса русского языка (НКРЯ), часть взята из публицистических книг воспоминаний, эссе, туристических проспектов.

Частотность употребления перечисленных ЛСГ глагольных предикатов в описании в публицистическом стиле представлена на рис. 1. За 100\% принято общее количество предикатов зрительной перцепции - 1015 .

При исследовании специфики употребления предикатов зрительной перцепции в описаниях публицистического стиля была выявлена более 
высокая частотность позиционных предикатов $(18,9 \%)$, предикатов направления $(18,5 \%)$ и положения в пространстве $(16,5 \%)$. В целом же специфика функционирования глагольных предикатов разных ЛСГ может быть связана с тематикой публикации в силу обслуживания публицистикой широкой сферы общественных отношений.

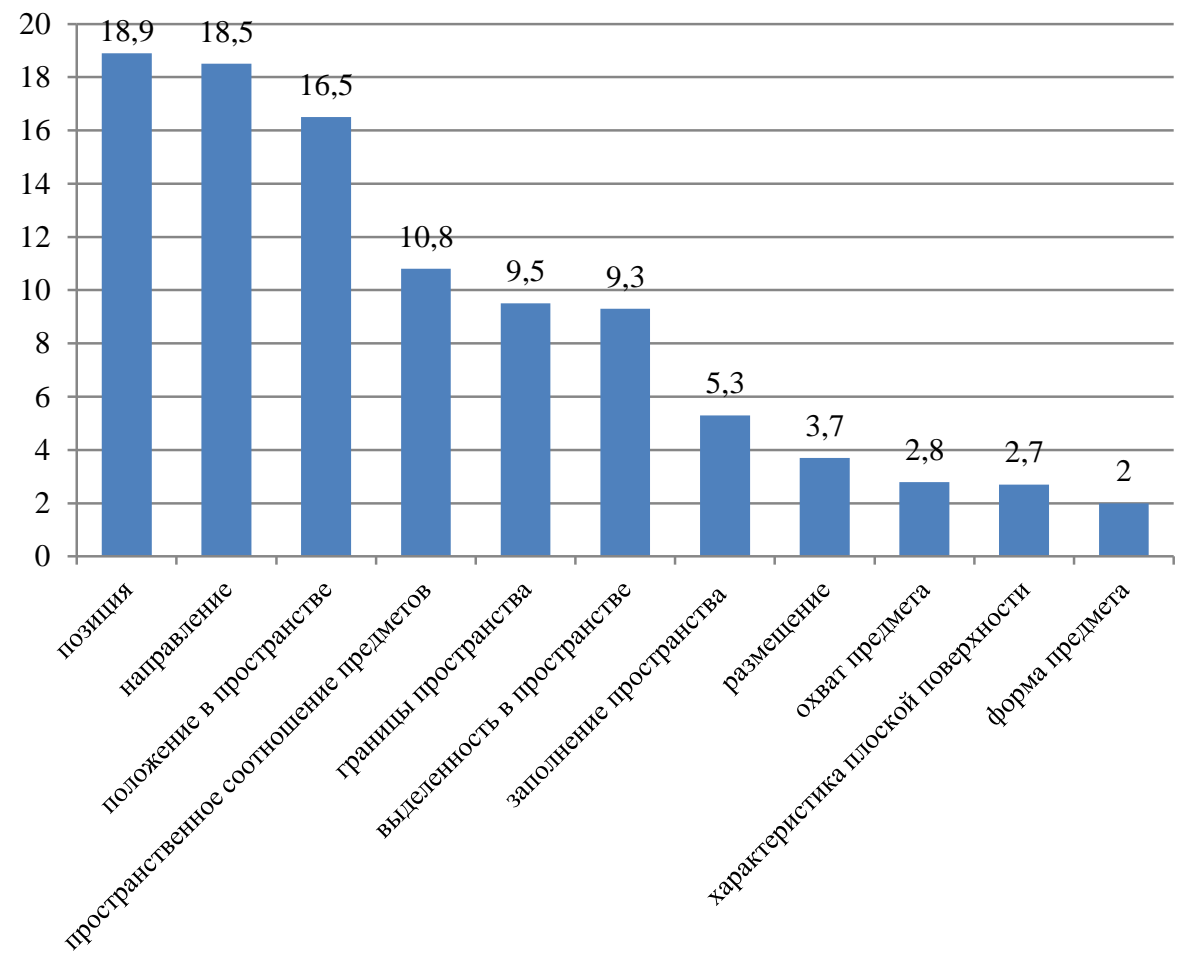

Рис. 1. Частотность употребления ЛСГ глагольных предикатов в описании публицистического стиля, \%

Помимо предикатов зрительной перцепции, в описании могут быть употреблены предикаты, презентующие другие модальности. Экспериментальная психология и физиология признали, что представление о пространстве человек получает не только с помощью зрения, но и посредством слуха, обоняния и т.д. Данные настоящего исследования позволяют сделать вывод, что в описательных текстах публицистического стиля используемые предикаты выражения слуховой, обонятельной, вкусовой, осязательной перцепции и недифференцированной модальности (называемые в статье интермодальными) могут служить выражению пространственных отношений. 
Включение в текст подобных единиц позволяет судить о пространственном расположении источника соответствующих ощущений: в случае, когда звуки хорошо различимы и могут быть дифференцированы, можно предположить более близкое размещение объекта - источника звука от воспринимающего; когда ощутимы определенные запахи, следовательно, объект-источник подобных ощущений находится на определенном расстоянии от наблюдателя. Таким образом, пространственные отношения в случае употребления интермодальных предикатов реализуются в оппозиции «далеко - близко».

Среди ЛСГ предикатов интермодальной семантики можно вычленить предикаты звучания (море шумит, ставни стучат, пчель жужжат и др.), обозначения ольфакторного состояния среды (маки пахнут, источают аромат, благоухают и др.), осязания (зной жжет, кожу щииплет, трава щекочет ноги и др.), вкуса (пирог горчит, кислит, присолен и др.), недифференцированной модальности (увствуется, ощущается холод, аромат, сладость и др.).

Частотность употребления ЛСГ интермодальных предикатов представлена на рис. 2. За 100\% принято общее количество предикатов зрительной перцепции -83 .

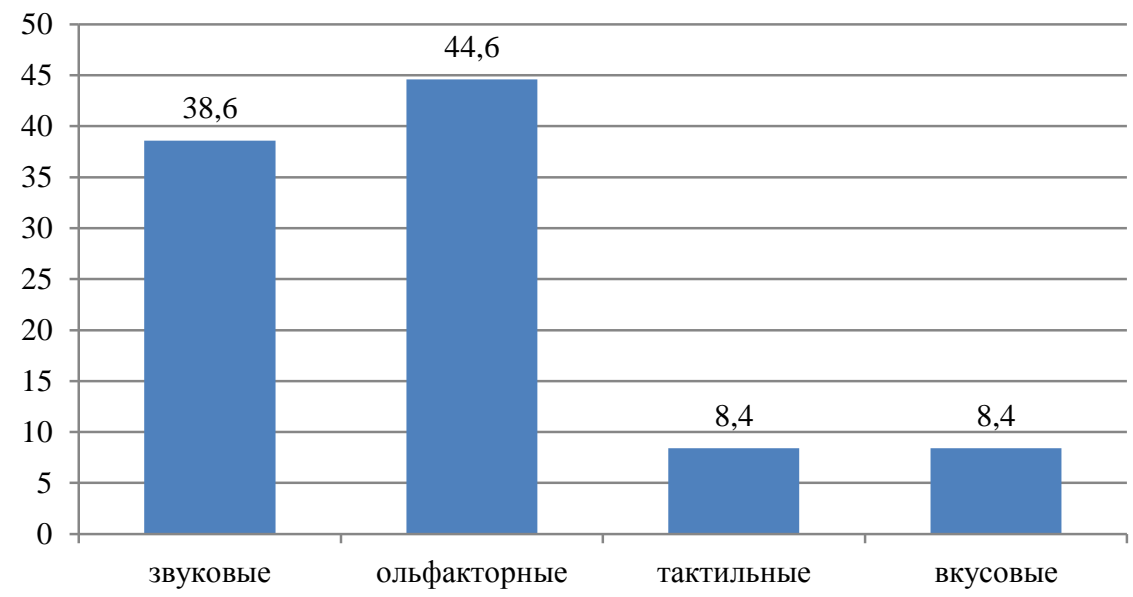

Рис. 2. Частотность употребления ЛСГ интермодальных глагольных предикатов в описании публицистического стиля, \%

При исследовании частотности употребления интермодальных предикатов было выявлено, что чаще всего в описании публицистического стиля фигурируют предикаты звука и запаха, что объясняется особой значимостью для человека слуховых и ольфакторных ощущений.

В приведенном ниже примере используются предикаты интермодальной семантики:

Канун Рождества. Пахнет блинами и конскими яблоками. Через Красную площуадь идет начальник отдела по борьбе с экономическими пре- 
ступлениями О., за ним - начальник отдела по борьбе с терроризмом 3., семечки лузгает (А. Мешков. Оборотень // Комсомольская правда, НКРЯ).

Здесь используется не только предикат ольфакторной модальности (nахнет блинами и конскими яблоками), но и акциональные единицы (uдет начальник, 3. лузгает семечки). В данном случае на значение действия в описании накладывается значение признака: действия, обозначенные предикатами движения (идет) и конкретного действия (лузгает) выступают как признаки описываемой картины.

Итак, помимо неакциональных предикатов, в состав описаний в публицистическом стиле могут быть включены и акциональные единицы, «теряющие» семантику действия. При обязательности полисубъектного строения подобных текстов (в отличие от моносубъектного повествования, где акциональные предикаты несут информацию о сменяющихся действиях одного субъекта) акциональные глагольные предикаты передают семантику бытийности, при этом важно не само действие, а лишь тот факт, что субъект, выполняющий это действие, наполняет собой описываемое пространство.

Таким образом, в описании публицистического стиля функционируют неакциональные предикаты зрительной перцепции, которые могут быть поделены на два блока с вычленением внутри них 11 ЛСГ, предикаты интермодальной семантики, а также акциональные глагольные предикаты, выполняющие в данном типе текста характеризующую функцию, - все они служат для передачи инвариантного пространственного значения, вербализуемого описанием.

\section{Лuтература}

1. Варфоломеева Ю.Н. Лингвокогнитивная модель текста типа «описание» // Научный диалог. 2019. № 11. С. 34-45.

2. Апресян Ю.Д. Лексикографические портреты (на примере глагола быть) // Научно-техническая информация. Серия 2: Информационные процессы и системы. 1992. № 3. С. 20-33.

3. Булысина Т.В., Шмелев А.Д. Языковая концептуализация мира (на материале русской грамматики). М. : Школа «Языки русской культуры», 1997. 576 с.

4. Васильев Л.М. Семантика русского глагола: учеб. пособие для слушателей факультетов повышения квалификации. М. : Высш. шк., 1981. 184 с.

5. Всеволодова М.В., Владимирский Е.Ю. Способы выражения пространственных отношений в современном русском языке. М. : Рус. яз., 1982. 264 с.

6. Гайсина Р.М. Лексико-семантическое поле глаголов отношения в современном русском языке. Саратов : Изд-во Сарат. ун-та, 1981. 195 с.

7. Падучева E.B. Русские глаголы восприятия: опыт описания структуры семантического поля // Русский язык: исторические судьбы и современность: междунар. конгресс исследователей русского языка: труды и материалы / под ред. М.Л. Ремневой и А.А. Поликарповой. М., 2001. С. 144-146.

8. Гукина Л.В. Семантическая классификация английских и русских глаголов со значением «расположение в пространстве» : автореф. дис. ... канд. филол. наук. Кемерово, 1997. $19 \mathrm{c}$.

9. Федосеева Л.Н. Категория локативности в современном русском языке : дис. ... д-ра филол. наук. М., 2013. 450 с. 
10. The Spatial Foundations of Language and Cognition / ed. by K.S. Mix, L.B. Smith, M. Gasser. Oxford : Oxford University Press, 2010. 328 p.

11. Филин Ф.П. О лексико-семантических группах слов // Очерки по теории языкознания. М., 1982. С. 229-239.

12. Васильев Л.М. Теория семантических полей // Вопросы языкознания. 1971. № 5. C. $105-113$.

13. Апресян Ю.Д. и др. Теоретические проблемы русского синтаксиса:. Взаимодействие грамматики и словаря. М. : Языки славянских культур, 2010. 408 с.

14. Баданина Л.П. Психология познавательных процессов. М. : Флинта: МПСИ, 2008. $236 \mathrm{c}$.

15. Варфоломеева Ю.Н. Семантика глагольных предикатов как свойство структурно-семантической модели текста типа «описание» : дис. ... канд. филол. наук. УланУдэ, 2008. $180 \mathrm{c.}$

16. Бохиева М.В. Функционирование безличных предложений в описательном типе речи : автореф. дис. ... канд. филол. наук. Улан-Удэ, 1998. 25 с.

17. Корпусова E.B. Прагматический аспект роли говорящего в функциональносмысловых типах речи «описание» и «повествование» : автореф. дис. ... канд. филол. наук. Кемерово, 2003. 24 с.

18. Омельченко Л.Н. Функционирование неполных двусоставных предложений с незамещенной позицией подлежащего в повествовании и описании : автореф. дис. ... канд. филол. наук. М., 1998. 16 с.

19. Русакова Н.В. Темпоральные (лексические) и референциальные свойства текста типа «описание» : дис. ... канд. филол. наук. Улан-Удэ, 2006. 164 с.

20. Кыркунова Л.Г. Официально-деловые тексты в аспекте функциональносмысловых типов речи : дис. ... канд. филол. наук. Пермь, 2007. 191 с.

21. Кыркунова Л.Г., Ширинкина М.А. Функционально-смысловые типы речи в текстах современных документов // Вестник Бурятского государственного университета. Язык. Литература. Культура. 2019. № 2. С. 36-40.

\section{Verb Predicate Classification in Descriptive Texts of the Publicistic Style}

Vestnik Tomskogo gosudarstvennogo universiteta. Filologiya - Tomsk State University Journal of Philology. 2021. 70. 16-26. DOI: 10.17223/19986645/70/2

Yulia N. Varfolomeeva, East Siberia State University of Technology and Management (UlanUde, Russian Federation).E-mail: yulvar83@mail.ru

Keywords: descriptive text, publicistic style, verb predicate, perception, classification of predicates, text model.

The article aims to make a semantic classification of verb predicates in descriptive texts of the publicistic style. The interest in the publicistic style is due to the fact that most research in the field of speech types is focused on the study of literary and scientific descriptions. The empirical base of the work consists of 684 descriptive texts of the publicistic style (from the Russian National Corpus, books of memoirs, essays, tourist brochures), in which 1,128 verb predicates are used. According to the linguo-cognitive method, the text model of the description includes the observer, who perceives some space, background (semantics of existence verbalized by verb predicates) and cognitively highlighted figures (actants). The article uses an integrated approach that combines semantic-contextual and descriptive techniques, and methods of component and quantitative analysis in the study of the semantics of verb predicates of description. The article proposes to identify three main groups of predicates functioning in descriptions of the publicistic style, which include: 1) predicates traditionally associated with the category of space - predicates of visual perception (the house is located close, is distanced from the fence, the windows shine in the sun, etc.); 2) units of intermodal semantics (flowers are fragrant, sounds are heard, skin is stinging, etc.); 3) action predicates (boy is reading a book, is running down the street, etc.). In the first group, two 
subgroups of predicates are subject to characterization. The first is predicates that call the spatial parameters of one object in relation to another. This subgroup of predicates includes units with specific meanings of location in space, position, scope of the object, filling of space, boundaries of space, direction, spatial relations of objects. The second subgroup is verb predicates that present their own spatial characteristics of the object, among which there are units with the semantics of the object's shape, characteristics of a flat surface, the position of objects in space, and selectivity in space based on light/color characteristics. Quantitative analysis allows stating the high frequency of positional predicates (18.9\%), directional predicates $(18.5 \%)$, and predicates of spatial position (16.5\%). Intermodal verb predicates express spatial relations in the opposition "far-close". Within this group, predicates of sound, designation of the olfactory state of the environment, touch, taste, and undifferentiated modality are distinguished. Most often, descriptions in the publicistic style include predicates of sound and smell, which is explained by the special significance of auditory and olfactory sensations for a person. Action predicates are used to denote the existence of an acting object in space. Thus, verb predicates of visual perception, intermodal and action semantics serve to indicate the existence of objects in space in descriptions in the publicistic style.

\section{References}

1. Varfolomeeva, Yu.N. (2019) Linguistic-Cognitive Text Model "Description". Nauchnyy dialog. 11. pp. 34-45. (In Russian). DOI: 10.24224/2227-1295-2019-11-34-45

2. Apresyan, Yu.D. (1992) Leksikograficheskie portrety (na primere glagola byt') [Lexicographic portraits (by the example of the verb to be)]. Nauchno-tekhnicheskaya informatsiya. Seriya 2: Informatsionnye protsessy i sistemy. 3. pp. 20-33.

3. Bulygina, T.V. \& Shmelev, A.D. (1997) Yazykovaya kontseptualizatsiya mira (na materiale russkoy grammatiki) [Linguistic conceptualization of the world (based on the material of Russian grammar)]. Moscow: Shkola "Yazyki russkoy kul'tury".

4. Vasil'ev, L.M. (1981) Semantika russkogo glagola: ucheb. posobie dlya slushateley fakul'tetov povysheniya kvalifikatsii [Semantics of the Russian verb: textbook for students of faculties of advanced training]. Moscow: Vysshaya shkola.

5. Vsevolodova, M.V. \& Vladimirskiy, E.Yu. (1982) Sposoby vyrazheniya prostranstvennykh otnosheniy $v$ sovremennom russkom yazyke [Ways of expressing spatial relationships in modern Russian]. Moscow: Rus. yaz.

6. Gaysina, R.M. (1981) Leksiko-semanticheskoe pole glagolov otnosheniya $v$ sovremennom russkom yazyke [Lexico-semantic field of relational verbs in modern Russian]. Saratov: Saratov State University.

7. Paducheva, E.V. (2001) Russkie glagoly vospriyatiya: opyt opisaniya struktury semanticheskogo polya [Russian verbs of perception: the experience of describing the structure of the semantic field]. In: Remneva, M.L. \& Polikanova, A.A. (eds) Russkiy yazyk: istoricheskie sud'by i sovremennost': mezhdunar. kongress issledovateley russkogo yazyka: trudy $i$ materialy [Russian language: historical destinies and modernity: International Congress of Russian Language Researchers: Works and Materials]. Moscow. pp. 144-146.

8. Gukina, L.V. (1997) Semanticheskaya klassifikatsiya angliyskikh i russkikh glagolov so znacheniem "raspolozhenie v prostranstve" [Semantic classification of English and Russian verbs with the meaning of location in space]. Abstract of Philology Cand. Diss. Kemerovo.

9. Fedoseeva, L.N. (2013) Kategoriya lokativnosti v sovremennom russkom yazyke [The category of locativity in modern Russian]. Philology Dr. Diss. Moscow.

10. Mix, K.S., Smith, L.B. \& Gasser, M. (eds) (2010) The Spatial Foundations of Language and Cognition. Oxford: Oxford University Press.

11. Filin, F.P. (1982) Ocherki po teorii yazykoznaniya [Essays on the theory of linguistics]. Moscow: Nauka. pp. 229-239.

12. Vasil'ev, L.M. (1971) Teoriya semanticheskikh poley [The theory of semantic fields]. Voprosy yazykoznaniya. 5. pp. 105-113. 
13. Apresyan, Yu.D. et al. (2010) Teoreticheskie problemy russkogo sintaksisa: Vzaimodeystvie grammatiki i slovarya [Theoretical problems of Russian syntax: Interaction of grammar and vocabulary]. Moscow: Yazyki slavyanskikh kul'tur.

14. Badanina, L.P. (2008) Psikhologiya poznavatel'nykh protsessov [Psychology of cognitive processes]. Moscow: Flinta: MPSI.

15. Varfolomeeva, Yu.N. (2008) Semantika glagol'nykh predikatov kak svoystvo strukturno-semanticheskoy modeli teksta tipa "opisanie" [Semantics of verb predicates as a property of the structural-semantic model of the text of the "description" type]. Philology Cand. Diss. Ulan-Ude.

16. Bokhieva, M.V. (1998) Funktsionirovanie bezlichnykh predlozheniy v opisatel'nom tipe rechi [The functioning of impersonal sentences in a descriptive type of speech]. Abstract of Philology Cand. Diss. Ulan-Ude.

17. Korpusova, E.V. (2003) Pragmaticheskiy aspekt roli govoryashchego $v$ funktsional'no-smyslovykh tipakh rechi "opisanie" $i$ "povestvovanie" [The pragmatic aspect of the speaker's role in the "description" and "narration" functional-semantic speech types]. Abstract of Philology Cand. Diss. Kemerovo.

18. Omel'chenko, L.N. (1998) Funktsionirovanie nepolnykh dvusostavnykh predlozheniy s nezameshchennoy pozitsiey podlezhashchego $v$ povestvovanii $i$ opisanii [The functioning of incomplete two-member sentences with an unsubstituted subject position in narration and description]. Abstract of Philology Cand. Diss. Moscow.

19. Rusakova, N.V. (2006) Temporal'nye (leksicheskie) i referentsial'nye svoystva teksta tipa "opisanie" [Temporal (lexical) and referential properties of the text of the "description" type]. Philology Cand. Diss. Ulan-Ude.

20. Kyrkunova, L.G. (2007) Ofitsial'no-delovye teksty $v$ aspekte funktsional'nosmyslovykh tipov rechi [Official business texts in the aspect of functional and semantic types of speech]. Philology Cand. Diss. Perm.

21. Kyrkunova, L.G. \& Shirinkina, M.A. (2019) Functional-Semantic Types of Speech in the Texts of Modern Documents. Vestnik Buryatskogo gosudarstvennogo universiteta. Yazyk. Literatura. Kul'tura - Bulletin of BSU. Language. Literature. Culture. 2. pp. 36-40. (In Russian). 